Article

\title{
Wind Loads on a Solar Panel at High Tilt Angles
}

\author{
Chin-Cheng Chou ${ }^{1}\left(\mathbb{D}\right.$, Ping-Han Chung $2, * \mathbb{C}$ and Ray-Yeng Yang ${ }^{2}$ \\ 1 Aerospace Science and Technology Research Center, National Cheng Kung University, Tainan City 701, \\ Taiwan; choucc@mail.ncku.edu.tw \\ 2 Department of Hydraulic and Ocean Engineering, National Cheng Kung University, Tainan City 701, \\ Taiwan; ryyang@mail.ncku.edu.tw \\ * Correspondence: e84046082@mail.ncku.edu.tw; Tel.: +886-6975175133
}

Received: 11 March 2019; Accepted: 15 April 2019; Published: 17 April 2019

Featured Application: This work aims to provide a good estimation of wind loads on a solar panel to ensure proper operation under the extreme wind strength and wave climates. The data will be also useful for the design of a mooring system.

\begin{abstract}
A solar photovoltaic system consists of tilted panels and is prone to extreme wind loads during hurricanes or typhoons. To ensure the proper functioning of the system, it is important to determine its aerodynamic characteristics. Offshore photovoltaic (PV) systems have been developed in recent years. Wind loads are associated with wind, wave climates, and tidal regimes. In this study, the orientation of a single panel is adjusted to different angles of tilt $\left(10^{\circ}-80^{\circ}\right)$ and angles of incidence for wind $\left(0^{\circ}-180^{\circ}\right)$ that are pertinent to offshore PV panels. The critical wind loads on a tilted panel are observed at lower angles of incidence for the wind, when the angle of tilt for the panel is greater than $30^{\circ}$.
\end{abstract}

Keywords: offshore PV; tilt angle; wind incidence angle; wind load

\section{Introduction}

Renewable energy is an integral part of the worldwide measures to address climate change and reduce environmental pollution. Power generation from photovoltaic (PV) systems is one of the most promising substitutes to the use of fossil fuel. The total capacity in operation was 303 GW in 2016 and 402 GW in 2017, which corresponds to energy supplies of 375 TWh in 2016 and 494 TWh in 2017 (20.4\% of the global renewable energy supply) [1]. PV panels are usually mounted on the rooftops of residential or commercial buildings. The systems are generally smaller than ground-mounted PV systems, for which land occupancy is a potential problem. PV systems that float on reservoirs or lakes use a pontoon structure for buoyancy, and there is a reduction in water evaporation and the temperature of solar cells. Trapani and Santafe [2] reviewed projects with floating PV systems from 2007 to 2013, and more installations are expected in the near future. Oceans cover approximately 71\% of the Earth's surface, and offshore environments can take full advantage of solar energy. Offshore PV systems have been proposed recently [3,4]. However, these installations are subject to greater wind loads in severe sea wave environments.

A PV system consists of tilted panels. Any PV system design requires an accurate estimation of wind-induced loads in order to ensure proper function. Many studies determine the aerodynamic characteristics of tilted panels or their supporting structure. Naeiji et al. [5] showed that the most critical parameter is the angle at which the panel is tilted, $\alpha$. Wind-induced loads are primarily due to pressure equalization for small angles of tilt and turbulence for large angles [6,7]. For a stand-alone panel that faces the direction of flow, Chung et al. [8] showed that an increase in $\alpha\left(15^{\circ}-25^{\circ}\right)$ results in a decrease in the unit sectional uplift coefficient in a uniform flow. There are strong suction forces near 
the front edge on the upper surface and slight wind-induced pressure on the lower surface. The mean spanwise pressure distributions have an inverted U-shape, which corresponds to the corner vortices. For the extreme cases of open terrain exposure, Stathopoulos et al. [9] showed that an increase in $\alpha$ $\left(20^{\circ}-45^{\circ}\right)$ leads to greater suction, and peak suction occurs at $\alpha=45^{\circ}$. An increase in the intensity of the freestream turbulence results in the upstream movement of a separation bubble and side-edge vortices. More intense pressure fluctuations and bending moments have been observed [10]. Aly [11] also showed that discrepancies in the available wind tunnel data may be due to the characteristics of the inflow turbulence. Chou et al. [12] studied the effect of wind direction, $\beta$. When $\beta=15^{\circ}-60^{\circ}$, there is greater suction on the upper surface near the windward corner. Chu and Tsao [13] showed that the maximum wind load occurs at $\beta=45^{\circ}$. There are maximum overturning moments for $\beta=45^{\circ}$ and $135^{\circ}$ [14]. A sheltering effect was reported by Radu et al. [15]. The wind loads on the tilted panels are significantly reduced by the presence of neighboring upwind panels, and the degree of reduction decreases quickly. Warsido et al. [16] also had similar results.

To harness solar energy, the performance of a PV system depends significantly on the angle at which the PV panels are tilted, their orientation, and shadowing [17-19]. The optimal value for $\alpha$ is achieved when the sunlight is perpendicular to the surface of the PV panels. Designs for a PV system often use wind loading standards, such as the American Society Civil Engineers (ASCE 7) [7,20], in order to calculate wind loads. However, wind loads can be larger than the ASCE 7 standard [21]. For PV panels floating directly on the surface of water, Trapani et al. [3] showed that the system is subject to salt water corrosion and to the dynamics of tides, wind, and waves. In extreme winds and waves, the wind loads on the PV panels in a harsh sea environment are not the same as the load on the PV panels that are on land. This study conducts a wind load analysis using wind tunnel experiment and numerical simulation for a stand-alone panel at high $\alpha$. The effect of $\beta$ is also determined. The data is useful for the detailed structural design of offshore PV panels.

\section{Experimental Setup}

Experiments were conducted in a wind tunnel at the Architecture and Building Research Institute. The tunnel is a closed-loop type with a contraction ratio of 4.71. The constant-area test section is $2.6 \mathrm{~m}$ (height) $\times 4 \mathrm{~m}$ (width) $\times 36.5 \mathrm{~m}$ (length). For a stand-alone panel $(60 \%$-scale commercial module), the test configuration is shown in Figure 1 . The length $(L)$ and width $(W)$ are $120 \mathrm{~cm}$ and $60 \mathrm{~cm}$, respectively. At $x / L=1.0$, the panel is $3 \mathrm{~cm}$ above the tunnel floor. The blockage ratio is up to $6.3 \%$. Note that a blockage correction is required for the mean surface pressure for a tilted panel if the blockage ratio is more than $10 \%$ [22].

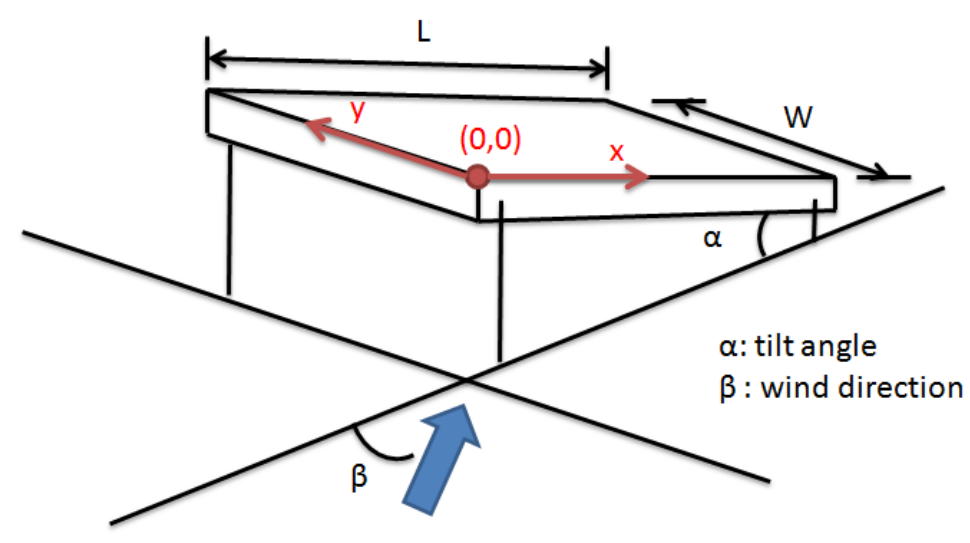

Figure 1. Test configuration for a stand-alone model.

This study determined the effect of $\alpha$ and $\beta$. Meteorological data (wave, wind, tide, and current) were collected from three near-shore buoys in Taiwan (Qigu, $23^{\circ} 05^{\prime \prime} 42^{\prime \prime} \mathrm{N}, 120^{\circ} 00^{\prime} 27^{\prime \prime} \mathrm{E}$; Hsinchu, $24^{\circ} 45^{\prime \prime} 19^{\prime \prime} \mathrm{N}, 120^{\circ} 50^{\prime} 12^{\prime \prime} \mathrm{E}$; and Longdong, $25^{\circ} 05^{\prime \prime} 48^{\prime \prime} \mathrm{N}, 121^{\circ} 55^{\prime} 19^{\prime \prime} \mathrm{E}$ ) [23]. In Qigu, the wind rose for 
the period of 2013-2017, and is shown in Figure 2. The most common values of $\beta$ are $210^{\circ}-225^{\circ}$ and $315^{\circ}-360^{\circ}$. Note that the wind direction is $30^{\circ}-45^{\circ}$ in Hsinchu, and $0^{\circ}$ in Longdong. The inclination of the PV panels depends on the waves. The historical data for typhoons shows that the maximum wave height and wind speed in Longdong are $17.12 \mathrm{~m}$ (mean period $=12.5 \mathrm{~s}$ during typhoon Soudelor, 2015 ) and $26.7 \mathrm{~m} / \mathrm{s}$ (mean period $=11.8 \mathrm{~s}$ during typhoon Soulik, 2013), respectively. The variation in $\alpha$ for the PV panels with respect to wind is $\pm 45^{\circ}$. Therefore, the setup for $\alpha$ is $10^{\circ}-80^{\circ}$ (in increments of $10^{\circ}$ ). The value for $\beta$ ranges from $0^{\circ}$ (facing the direction of the wind) to $180^{\circ}$ (in increments of $15^{\circ}$ ). Note that the angle between the PV panels and their base is not changed in sea wave environments, which is not exactly the same as the case for the experimental setup.

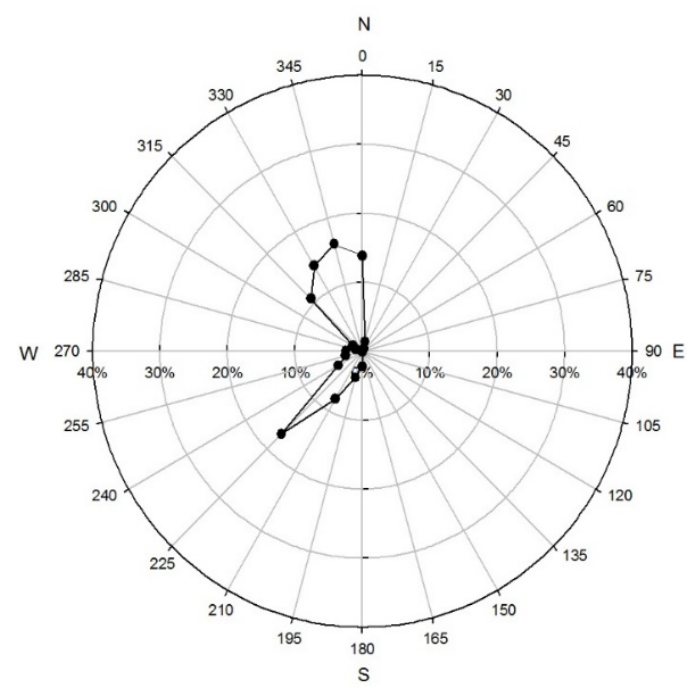

Figure 2. Probability distribution for the incidence of wind for the Qigu buoy (2013-2017).

The experiments were conducted in a uniform flow. The freestream velocity was set at $14.5 \pm 0.1 \mathrm{~m} / \mathrm{s}$, measured using a Pitot-static tube, and the turbulence intensity was $0.3 \%$. Chung et al. [24] showed that there is greater expansion on the upper surface, and more positive pressure on the lower surface of a tilted panel when the intensity of the turbulence increases. The front edge of the test model was located $2.8 \mathrm{~m}$ from the inlet of the working section. A Reynolds number of $1.17 \times 10^{6}$ is based on the length of the tilted panel. Chung et al. [25] reported that a tilted panel is not affected by the Reynolds number.

A total of 330 pressure taps were drilled on the test model and were connected to flexible polyvinyl chloride tubing that is $1.1-\mathrm{mm}$ in diameter and $60-\mathrm{cm}$ in length, so the phase distortion has little effect on the measured peak pressure [26]. As there are strong pressure gradients (flow separation and reattachment) near the front edge of the tilted panel, $92 \%$ pressure taps were machined on the first two-thirds of the upper and lower plate surfaces. SCANVALVE multichannel modules (Model ZOC 33/64Px 64-port; Model RAD3200 pressure transducer) were used for the surface pressure measurements. The full-scale range of the sensors was $\pm 2490 \mathrm{~Pa}$, with an accuracy of $\pm 0.15 \%$ full scale. The sampling rate was $250 \mathrm{~Hz}$ and each record contained 32,768 data points. A Pitot-static tube, which was at the same height as the front edge of the tilted panel and $2.8 \mathrm{~m}$ from the inlet of the working section, was used to measure the static pressure, $p_{\infty}$, and the dynamic pressure, $q$, of the incoming flow. The mean surface pressure coefficient was given as $C_{p}\left(=\left(p-p_{\infty}\right) / q\right)$. The uplift coefficient, $C_{L}\left(=\frac{1}{A} \int_{A} \Delta C_{p} \cos (\alpha) d A\right)$, was calculated by integrating the differential mean surface pressure distributions $\left(\Delta C_{p}=C_{p, u p}-C_{p, l o w}\right)$ between the upper and lower surfaces of the tilted panel. 


\section{Results and Discussion}

\subsection{Longitudinal Pressure Distributions}

The $C_{p}$ distributions on the centerline $(y / W=0.5)$ for $\beta=0^{\circ}$ are shown in Figure 3. The origin of the coordinates $(x / L=0$ and $y / W=0)$ is located at the left corner of the tilted panel. The solid and hollow symbols represent the value of $C_{p}$ on the upper and lower surface, respectively. Suction, which corresponds to flow separation, is observed on the upper surface for all of the test cases. For $\alpha=30^{\circ}$, the value of $C_{p}$ decreases significantly near the front edge, reaches a peak value of -1.66 , and approaches a more moderate level in the second half of the panel. At larger angles of tilt $\left(\alpha \geq 50^{\circ}\right)$, there are flattened $C_{p}$ distributions, for which the value of $C_{p}$ ( -0.72 to -0.82$)$ for a specific value of $\alpha$ varies by less than $4 \%$. On the lower surface, there is a slight expansion near the front and rear edges for $\alpha=10^{\circ}$. Positive pressure is observed and the magnitude increases as $\alpha$ increases. This shows that the localized load is the most significant near the front edge for $\alpha=30^{\circ}$. There is also a slight variation in the magnitude of $C_{p}(0.91$ to 0.93$)$ for $\alpha=50^{\circ}-80^{\circ}$, so the uplift lift force is approximately constant for larger angles of tilt $\left(\alpha \geq 50^{\circ}\right)$, when $\beta=0^{\circ}$.

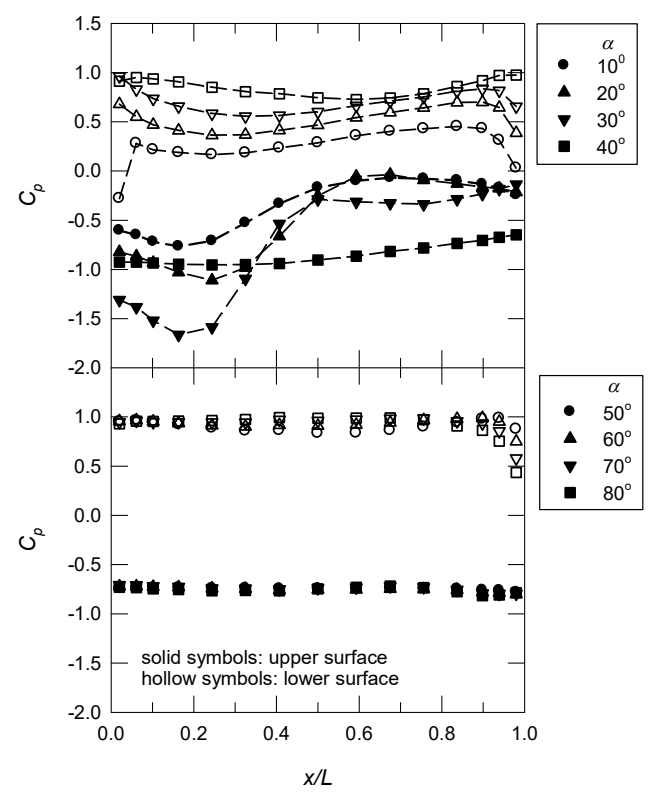

Figure 3. Mean longitudinal pressure distributions at $y / W=0.5 ; \beta=0^{\circ}$.

The $C_{p}$ distributions for $\beta=30^{\circ}, 45^{\circ}$, and $135^{\circ}$ are shown in Figures $4-6$. These correspond to the most common direction for the wind for the meteorological data. For $\beta=30^{\circ}$ and $45^{\circ}$, there is greater suction on the upper surface for $\alpha=10^{\circ}$ and $20^{\circ}$. A flow expansion in the second half of the panel is also observed, particularly for $\beta=45^{\circ}$. This agrees with the results of Chou et al. [12]. Suction near the front edge is mitigated for $\alpha=30^{\circ}$, and there is a flatter $C_{p}$ distribution. The value of $C_{p}$ is approximately the same for $\alpha=40^{\circ}-80^{\circ}(-0.701$ to -0.711$)$, and the effect of $\alpha$ is minimal. Its amplitude increases slightly more than that for $\beta=0^{\circ}\left(C_{p}=-0.743\right.$ to -0.756$)$. For $\beta=135^{\circ}$, a small degree of suction is observed near the front face, and the value of $C_{p}$ increases downstream. The value of $\alpha$ has an obvious effect, in that the amplitude of $C_{p}$ increases as $\alpha$ increases. There is a slight flow expansion near the rear edge for $\alpha=10^{\circ}$ and $20^{\circ}$. On the lower surface for $\beta=30^{\circ}$ and $45^{\circ}$, there is a fairly uniform $C_{p}$ distribution for specific values of $\alpha$. The value of $C_{p}$ is positive, except for the case of $\alpha=10^{\circ}$ near the rear edge. This shows that the uplift force increases as $\alpha$ increases. Suction on the lower surface for $\beta=135^{\circ}$ produces greater downward force, particularly for $\alpha \geq 30^{\circ}$. 


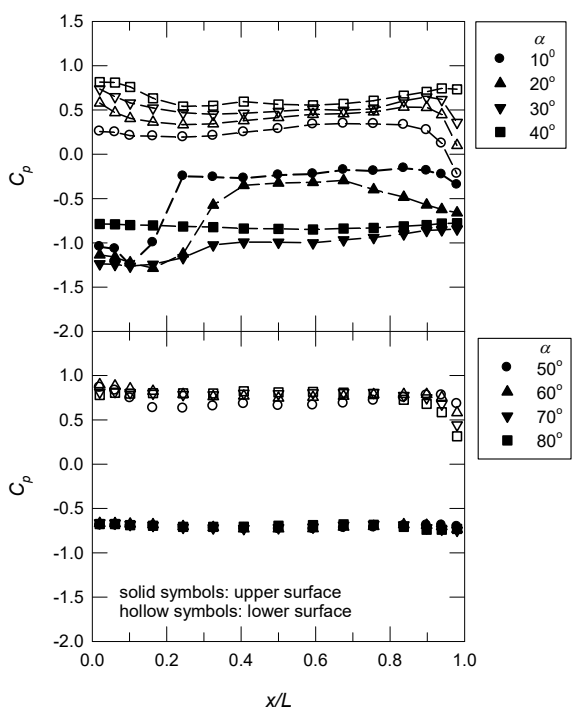

Figure 4. Mean longitudinal pressure distributions at $y / W=0.5 ; \beta=30^{\circ}$.

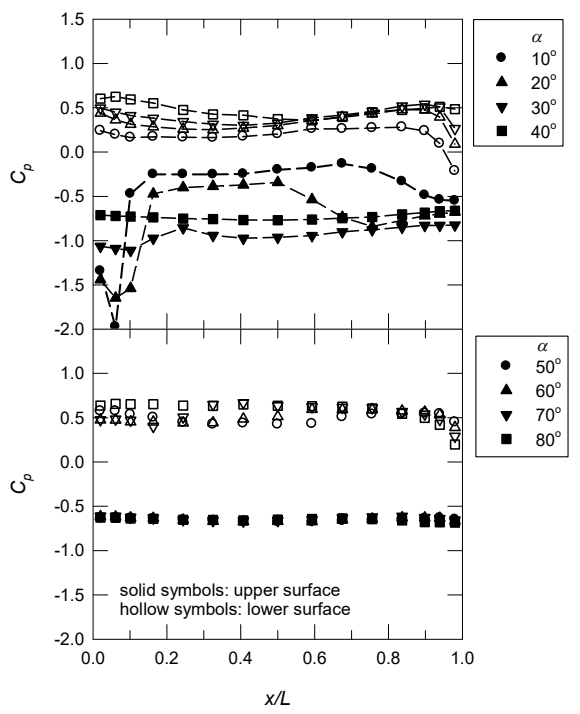

Figure 5. Mean longitudinal pressure distributions at $y / W=0.5 ; \beta=45^{\circ}$.

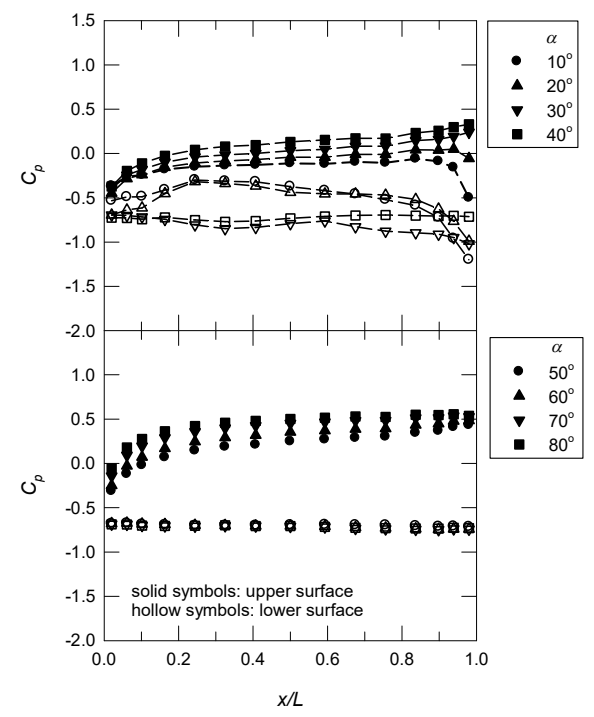

Figure 6. Mean longitudinal pressure distributions at $y / W=0.5 ; \beta=135^{\circ}$. 


\subsection{Spanwise Pressure Distributions}

At $x / L=0.5$, the spanwise pressure, $C_{s p}$, and distributions for $\beta=0^{\circ}$ are shown in Figure 7 . There is suction (negative $C_{s p}$ ) on the upper surface for all of the test cases. Inverted $U$-shaped distributions are observed for small $\alpha$, particularly for $\alpha=20^{\circ}$ and $30^{\circ}$. This produces strong corner vortices, which is in agreement with the results of Chung et al. [10]. For $\alpha \geq 40^{\circ}$, the $C_{s p}$ distributions show a small degree of variation. On the lower surface, the footprints of the corner vortices are also visible. The peak value of $C_{s p}(0.29$ to 0.99$)$ at $y / W=0.5$ increases as $\alpha$ increases. The increase in $C_{s p}$ as $\alpha$ increases is more significant for $\alpha \leq 50^{\circ}$.

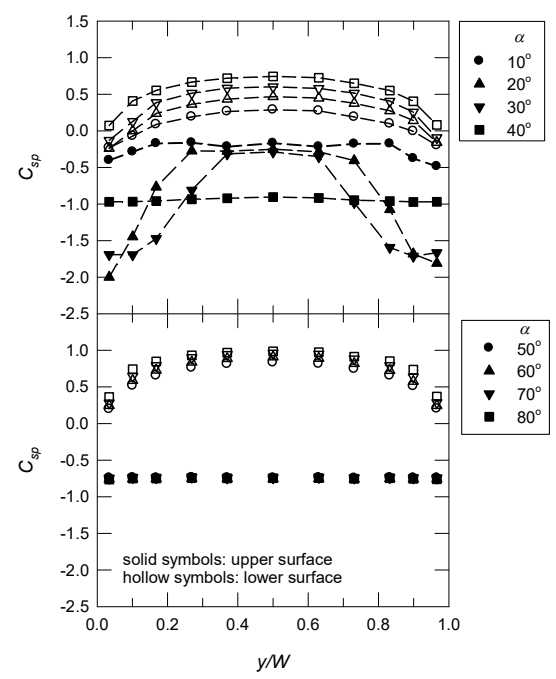

Figure 7. Mean spanwise pressure distributions at $x / L=0.5 ; \beta=0^{\circ}$.

Figures 8 and 9 show that $\beta=30^{\circ}$ and $45^{\circ}$. There are flattened $C_{s p}$ distributions in the left half of the panel for $\alpha=10^{\circ}$ and $20^{\circ}$. The expansion and compression near the right edge corresponds to the formation of a separation bubble or corner vortices. The variation in $C_{s p}$ for $\alpha \geq 40^{\circ}$ is less than $3 \%$. An increase in the value of $C_{s p}(-0.738$ to -0.693$)$ is associated with greater $\alpha$ (less suction). An increase in the value of $C_{s p}$ is observed from the left to the right edges, so there is a greater uplift force near the right edge. Figure 10 shows that for $\beta=135^{\circ}$, the wind blows over the lower surface of the tilted panel. The $C_{s p}$ distributions on the lower surface show similar patterns to those on the upper surface for $\beta=45^{\circ}$. This demonstrates that there is an increase in the downward force from the left to right edges.

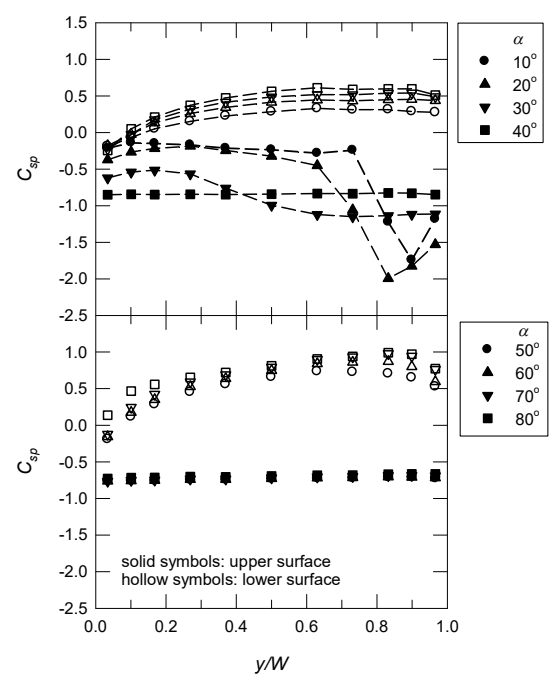

Figure 8. Mean spanwise pressure distributions at $x / L=0.5 ; \beta=30^{\circ}$. 


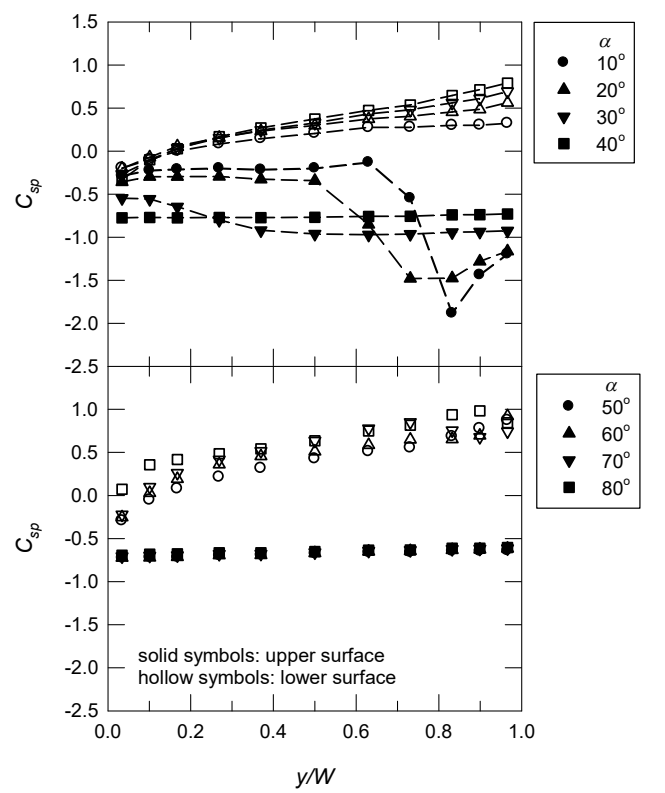

Figure 9. Mean spanwise pressure distributions at $x / L=0.5 ; \beta=45^{\circ}$.

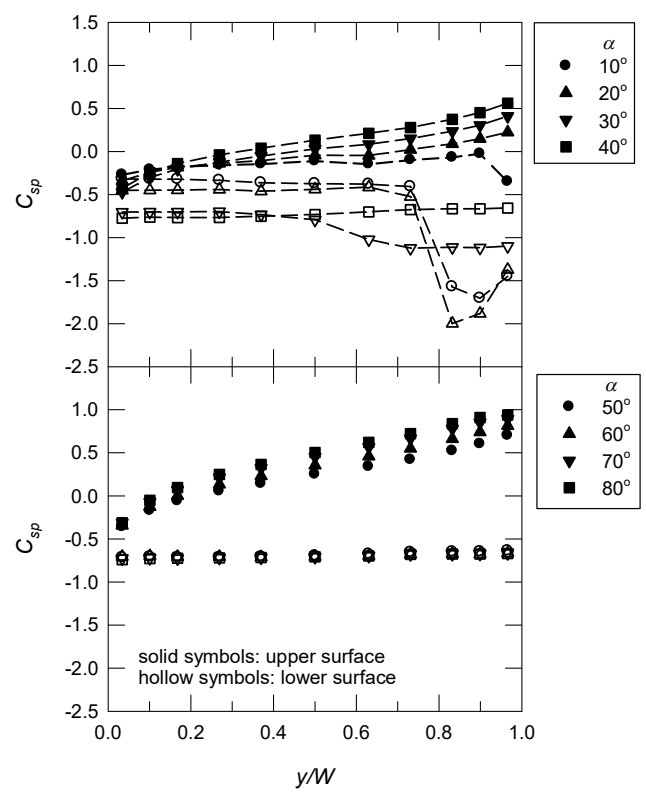

Figure 10. Mean spanwise pressure distributions at $x / L=0.5 ; \beta=135^{\circ}$.

\subsection{The Uplift Coefficient}

The value of $C_{L}$ is calculated by integrating $\Delta C_{p}$. Examples of $C_{p}$ distributions on the upper and lower surface $\left(\alpha=30^{\circ}\right.$ and $\beta=0^{\circ}$ ) are shown in Figure 11. There is a symmetrical spanwise pressure distribution with respect to $y / W=0.5$. The flow expansion and corner vortices on the first half of the panel result in a relatively large negative value of $C_{p}$ for the upper surface. A positive value of $C_{p}$ is observed on the lower surface. Near the front and rear edges, a more positive value for $C_{p}$ corresponds to the blocking effect of the tilted panel.

The variation in $C_{L}$ with respect to $\alpha$ and $\beta$ is shown in Figure 12. The value of $C_{L}$ (uplift force) is negative for $\beta<90^{\circ}$, and is relatively small for $\beta=90^{\circ}$. The lowest value for $C_{L}$ is for $\alpha=30^{\circ}$ to $40^{\circ}$. This is similar to the observation by Stathopoulos et al., who noted that peak suction occurs at $\alpha=45^{\circ}$ [9]. The positive value for $C_{L}$ for $\beta \geq 105^{\circ}$ represents a downward force. A kink is also observed at $\alpha=50^{\circ}$. 


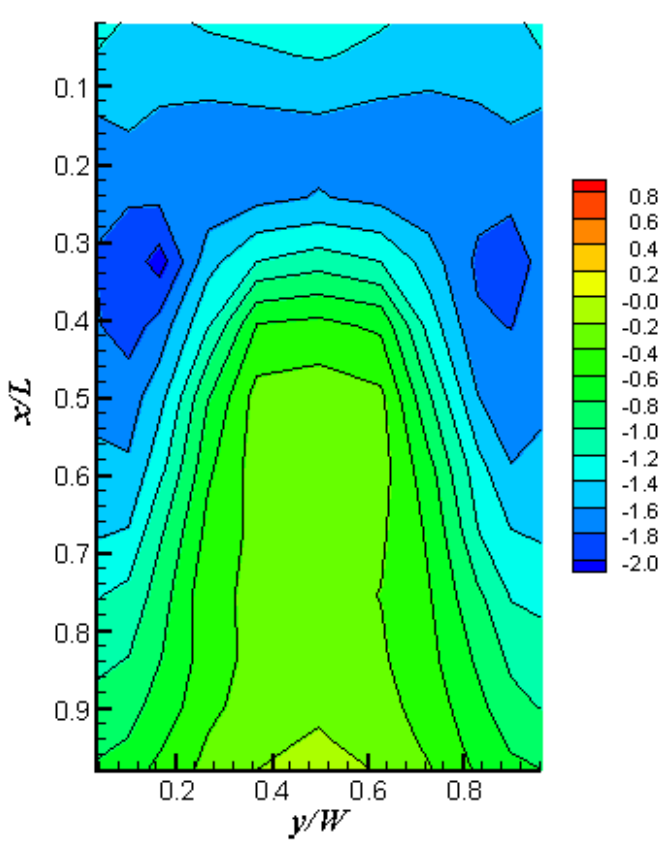

(a)

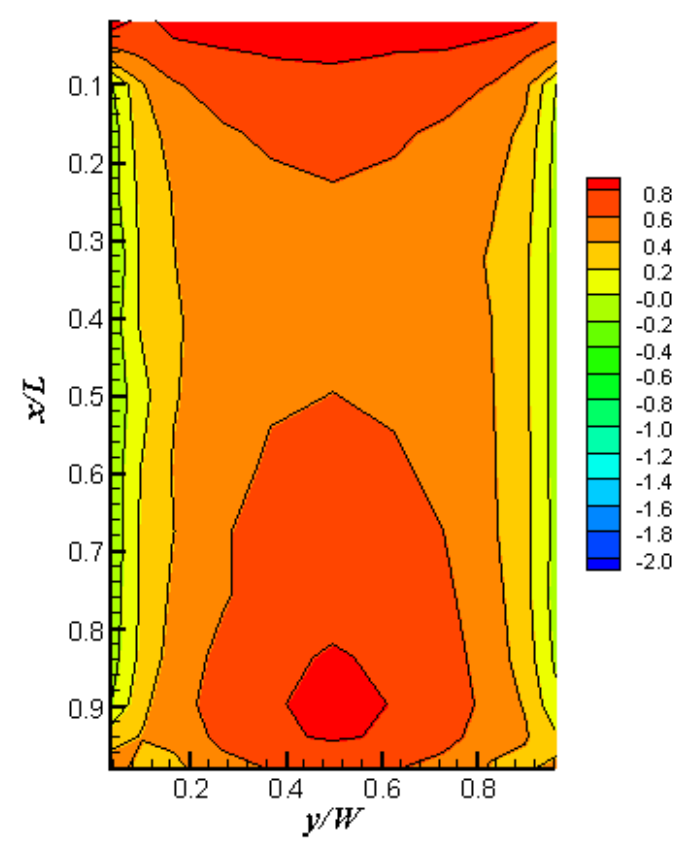

(b)

Figure 11. Pressure coefficient contours for $\alpha=30^{\circ}$ and $\beta=0^{\circ}$ for (a) the upper surface and (b) the lower surface.

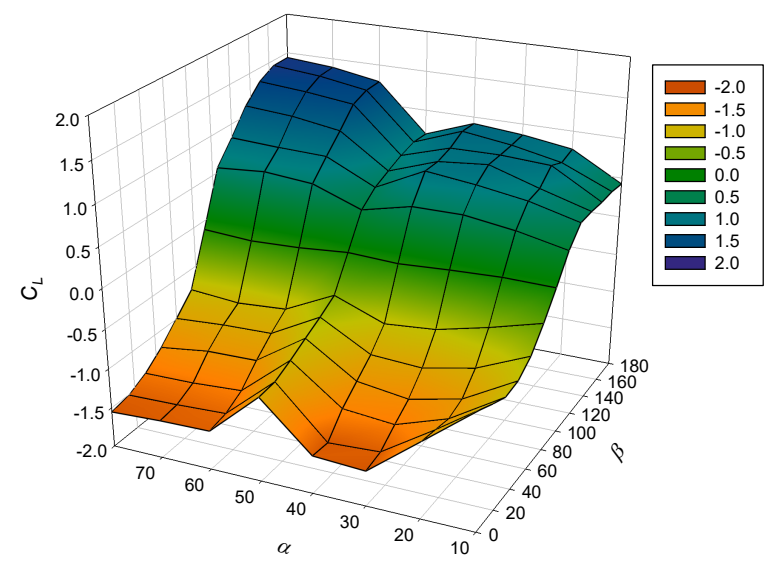

Figure 12. Uplift coefficient.

For a specific value of $\beta$, the effect of $\alpha$ on $C_{L}$ is shown in Figure 13. For $\beta \leq 75^{\circ}, C_{L}$ decreases linearly as $\alpha$ increases $\left(\leq 30^{\circ}\right)$, following an increase for $\alpha=50^{\circ}$. The value of $C_{L}$ at high $\alpha\left(60^{\circ}\right.$ to $\left.80^{\circ}\right)$ is approximately the same as that at $\alpha=30^{\circ}$ and $40^{\circ}$. Wind loads on a tilted panel at lower $\beta$ require caution at the design stage. An opposite effect is observed for $\beta \geq 90^{\circ}$. The variation of $C_{L}$ with $\alpha$ $\left(\geq 60^{\circ}\right)$ is minimal. The value of $C_{L}$ also varies linearly with $\alpha\left(\leq 30^{\circ}\right)$ for a specific value of $\beta$. Figure 14 shows that the value of $C_{L}$ increases as the value of $\alpha$ increases. The value of $d C_{L} / d \alpha$ increases from a negative to a positive value when there is an increase in $\beta$. Therefore, the uplift force is more significant at lower values of $\beta$, so $d C_{L} / d \alpha=-0.0542+7.376 \times 10^{-4} \beta-1.67 \times 10^{-6} \beta^{2}$. Figure 15 shows the effect of $\beta$ on $C_{L}$ for a specific value of $\alpha$. For $\alpha=10^{\circ}$ and $20^{\circ}$, the value of $C_{L}$ decreases initially and the lowest value of $C_{L}$ is for $\beta=30^{\circ}$, following an increase in $C_{L}$ with $\beta$. There is a smaller variation in $C_{L}$ for $\beta \geq 120^{\circ}$. For $\alpha \geq 30^{\circ}$, the value of $C_{L}$ increases as the value of $\beta$ increases. 


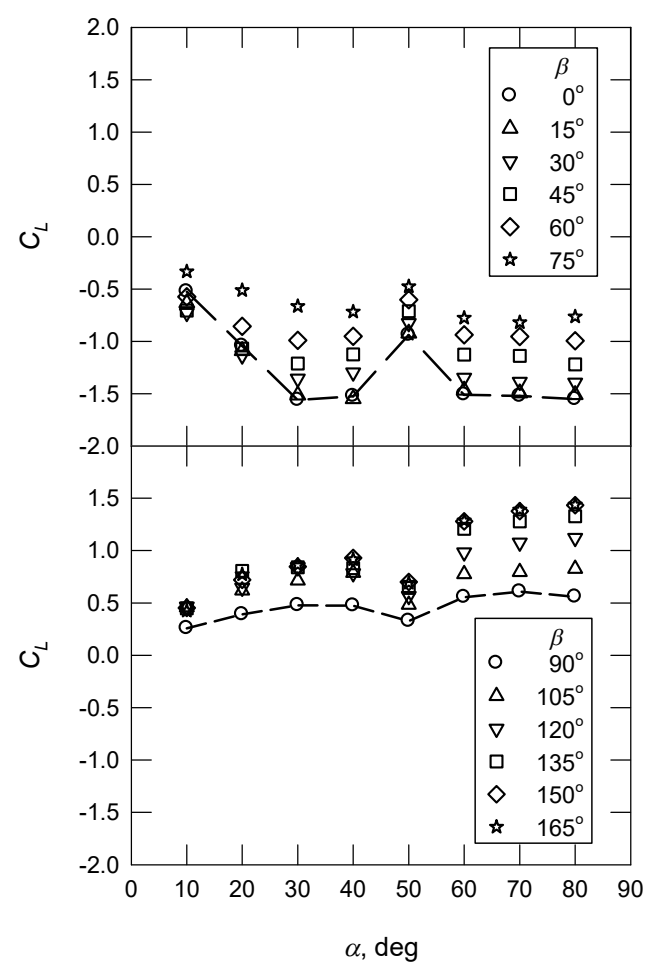

Figure 13. Uplift coefficient for a specific value of $\beta$.

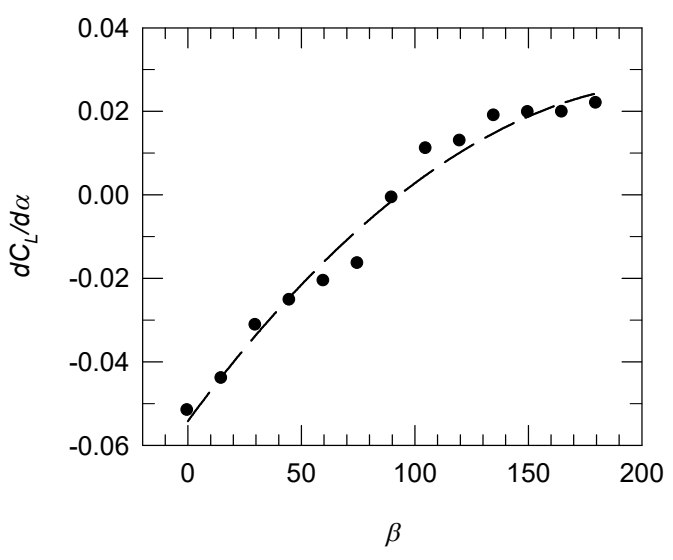

Figure 14. The effect of $\beta$ on $d C_{L} / d \alpha$.

For the numerical study, 3D incompressible RANS simulations of wind flow over a stand-alone PV panel in full scale were performed using a steady finite volume solver of second-order accuracy (ANSYS Fluent 13) for the value of $\alpha$ of $10^{\circ}$ to $40^{\circ}$ (in increments of $10^{\circ}$ ) and the value of $\beta$ of $0^{\circ}$ to $180^{\circ}$ (in increments of $45^{\circ}$ ). The semi-implicit method for the pressure-linked equation (SIMPLE) is used. The SST $\kappa-\omega$ turbulence model [27] models flows with separation reasonably well. However, it is necessary to mesh down (wall spacing; $y^{+} \sim 1$ ). Therefore, this parametric study uses the realizable $k-\varepsilon$ turbulence model $\left(y^{+} \sim 30\right)$ [28], in which a modified transport equation for the dissipation rate is derived from an exact equation for the transport of the mean-square vorticity equation. The computational domain is an upstream fetch of $5 \mathrm{~L}$ and a downstream length of $10 \mathrm{~L}$. The height and width are $5 \mathrm{~L}$ and $6 L$, respectively.

The grid is created using the grid generating software, Pointwise. Once a solution is obtained and the value of $y^{+}$for the first grid point from the wall is verified, the grid sensitivity (number of grids, $G=20-40.0$ million) is performed using the value of $C_{p}$ on the upper and lower surfaces for $\alpha=10^{\circ}$ 
and $\beta=0^{\circ}$. The difference in $C_{p}$ for $G=35$ and 40 million is less than $1.5 \%$. Therefore, the total number of unstructured grids that is used is approximately 35 million.

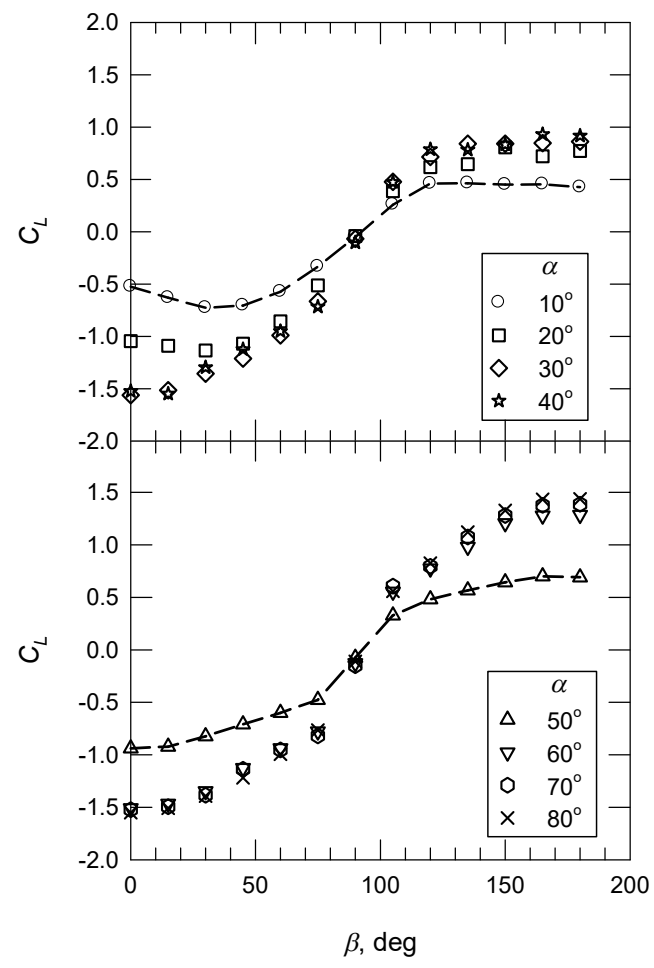

Figure 15. Uplift coefficient for a specific value of $\alpha$.

At the domain inlet, there is a uniform freestream flow of $15 \mathrm{~m} / \mathrm{s}$. The results are shown in Figure 16. For $\alpha=10^{\circ}-40^{\circ}$, the variations in the value of $C_{L}$ with $\beta$ is similar to that for the experimental data. The maximum difference between the numerical and experimental results is up to $18 \%$, which occurs for the peak value of $C_{L}$ or stronger corner vortices for a specific value of $\alpha$ (i.e., $\beta=45^{\circ}$ for $\alpha=10^{\circ}$ and $20^{\circ}$ ). Further study of the effect of scaling on the wind flow field is required.

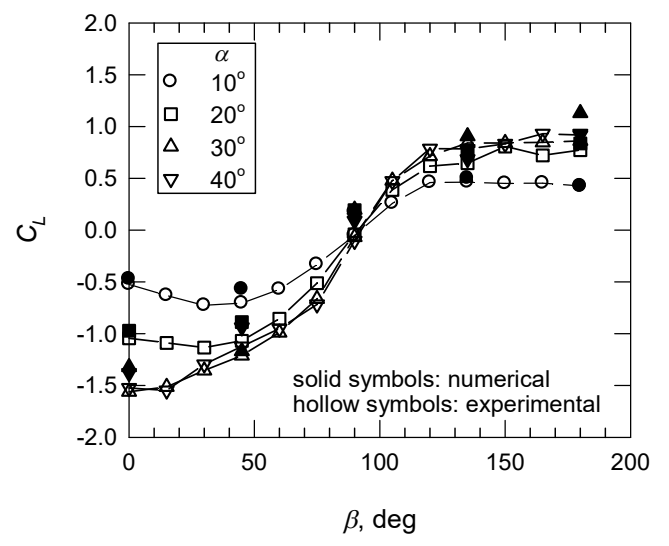

Figure 16. Uplift coefficient: numerical and experimental results.

\section{Conclusions}

Meteorological data were collected from three near-shore buoys in Taiwan. For a sea wave environment, this study determines the effect of $\alpha$ and $\beta$ on wind loads on a tilted panel. At lower angles of tilt $\left(\leq 40^{\circ}\right)$, the experimental results agree with those of previous studies. Greater suction on the upper surface produces flow expansion and corner vortices. The uplift force increases linearly with 
$\alpha$. When there is an increase in $\beta$, expansion and compression are observed near the right edge, which produce a greater uplift force. The increase in the uplift coefficient with $\alpha$ changes from a negative to a positive value $\left(d C_{L} / d \alpha=-0.0542+7.376 \times 10^{-4} \beta-1.673 \times 10^{-6} \beta^{2}\right.$ for $\left.\alpha \leq 30^{\circ}\right)$. The variation of $C_{L}$ with $\beta$ using a numerical simulation is similar to that for the experimental data. At high angles of tilt, there is a kink in the curve for $C_{L}$ at $\alpha=50^{\circ}$. A small variation in $C_{L}$ is observed at high angles of tilt $\left(\geq 60^{\circ}\right)$, for which the magnitude is approximately the same as that at $\alpha=30^{\circ}$ and $40^{\circ}$. Caution is necessary when there are wind loads on a tilted panel at lower values of $\beta$, when the value of $\alpha$ is greater than $30^{\circ}$.

Author Contributions: Conceptualization/methodology/data curation, C.-C.C. and P.-H.C.; writing (original draft preparation), P.-H.C.; writing (review and editing), R.-Y.Y.

Funding: This research was funded by Industrial Technology Research Institute.

Acknowledgments: The numerical simulation was conducted by K.C. Su, Aerospace Science and Technology Research Center, National Cheng Kung University.

Conflicts of Interest: The authors declare no conflict of interest.

\section{Nomenclature}

$\begin{array}{ll}C_{L} & \begin{array}{l}\text { uplift coefficient } \\ \text { pressure coefficient in the longitudinal direction, } \\ \left(p-p_{\infty}\right) / q\end{array} \\ C_{p} & \text { pressure coefficient on the lower surface } \\ C_{p, l o w} & \text { pressure coefficient in the spanwise direction } \\ C_{s p} & \text { pressure coefficient on the upper surface } \\ C_{p, u p} & \text { length of tilted panel } \\ L & \text { freestream static pressure } \\ p_{\infty} & \text { dynamic pressure } \\ q & \text { width of tilted panel } \\ W & \text { coordinate in the longitudinal direction } \\ \mathrm{x} & \text { coordinate in the spanwise direction } \\ \mathrm{y} & \text { angle of tilt } \\ \alpha & \text { wind incidence angle } \\ \beta & \text { differential pressure, } C_{p, \text { up }}-C_{p, l o w} \\ \Delta C_{p} & \end{array}$

\section{References}

1. Mauthner, F.; Weiss, W.; Spörk-Dür, M. Solar Heat Worldwide; AEE-Institute for Sustainable Technologies: Gleisdorf, Austria, 2018.

2. Trapani, K.; Santafe, M.R. A review of floating photovoltaics installations: 2007-2013. Prog. Photovolt. 2015, 23, 524-532. [CrossRef]

3. Trapani, K.; Millar, D.L.; Smith, H.C. Novel offshore application of photovoltaics in comparison to conventional marine renewable energy technologies. Renew. Energy 2013, 50, 879-888. [CrossRef]

4. Sahu, A.; Yadav, N.; Sudhakar, K. Floating photovoltaic power plant: A review. Renew. Sustain. Rev. 2016, 66, 815-824.

5. Naeiji, A.; Raji, F.; Zisis, I. Wind loads on residential scale rooftop photovoltaic panels. J. Wind. Eng. Ind. Aerodyn. 2017, 168, 228-246. [CrossRef]

6. Cao, J.; Yoshida, A.; Saha, P.K.; Tamura, Y. Wind loading characteristics of solar arrays mounted on flat roofs. J. Wind. Eng. Ind. Aerodyn. 2013, 123, 214-225. [CrossRef]

7. Kopp, G.A.; Banks, D. Use of the Wind Tunnel Test Method for Obtaining Design Wind Loads on Roof-Mounted Solar Arrays. J. Struct. Eng. 2013, 139, 284-287. [CrossRef]

8. Chung, K.-M.; Chang, K.-C.; Chou, C.-C. Wind loads on residential and large-scale solar collector models. J. Wind. Eng. Ind. Aerodyn. 2011, 99, 59-64. [CrossRef]

9. Stathopoulos, T.; Zisis, I.; Xypnitou, E. Local and overall wind pressure and force coefficients for solar panels. J. Wind. Eng. Ind. Aerodyn. 2014, 125, 195-206. [CrossRef] 
10. Chung, K.-M.; Chou, C.-C.; Chang, K.-C.; Chen, Y.-J. Effect of a vertical guide plate on the wind loading of an inclined flat plate. Wind. Struct. Int. J. 2013, 17, 537-552. [CrossRef]

11. Aly, A.M. On the evaluation of wind loads on solar panels: The scale issue. Sol. Energy 2016, 135, 423-434. [CrossRef]

12. Chou, C.-C.; Chung, K.-M.; Chang, K.-C. Wind Loads of Solar Water Heaters: Wind Incidence Effect. J. Aerodyn. 2014, 2014, 1-10. [CrossRef]

13. Chu, C.-R.; Tsao, S.-J. Aerodynamic loading of solar trackers on flat-roofed buildings. J. Wind. Eng. Ind. Aerodyn. 2018, 175, 202-212. [CrossRef]

14. Jubayer, C.M.; Hangan, H. Numerical simulation of wind effects on a stand-alone ground mounted photovoltaic (PV) system. J. Wind. Eng. Ind. Aerodyn. 2014, 134, 56-64. [CrossRef]

15. Radu, A.; Axinte, E. Wind forces on structures supporting solar collectors. J. Wind. Eng. Ind. Aerodyn. 1989, 32, 93-100. [CrossRef]

16. Warsido, W.P.; Bitsuamlak, G.T.; Barata, J.; Chowdhury, A.G. Influence of spacing parameters on the wind loading of solar array. J. Fluids Struct. 2014, 48, 295-315. [CrossRef]

17. Guo, M.; Zang, H.; Gao, S.; Chen, T.; Xiao, J.; Cheng, L.; Wei, Z.; Sun, G. Optimal tilt angle and orientation on photovoltaic modules using HS algorithm in different climates in China. Appl. Sci. 2017, 7, 1028. [CrossRef]

18. Lau, K.; Tan, C.; Yatim, A. Effects of ambient temperatures, tilt angles, and orientations on hybrid photovoltaic/diesel systems under equatorial climates. Renew. Sustain. Rev. 2018, 81, 2625-2636. [CrossRef]

19. Castellano, N.N.; Parra, J.A.G.; Valls-Guirado, J.; Manzano-Agugliaro, F. Optimal displacement of photovoltaic array's rows using a novel shading model. Appl. Energy 2015, 144, 1-9. [CrossRef]

20. ASCE 7-10. Minimum Design Loads for Buildings and Other Structures; American Society of Civil Engineers: Reston, VA, USA, 2010.

21. Bender, W.; Waytuck, D.; Wang, S.; Reed, D. In situ measurement of wind pressure loadings on pedestal style rooftop photovoltaic panels. Eng. Struct. 2018, 163, 281-293. [CrossRef]

22. Chung, K.-M.; Chen, Y.-J. Effect of High Blockage Ratios on Surface Pressures of an Inclined Flat Plate. J. Eng. Arch. 2016, 4, 1-16. [CrossRef]

23. Central Weather Bureau (CWB), Ministry of Transportation and Communication. Available online: https: //www.cwb.gov.tw/V7/climate/marine_stat/wave.htm (accessed on 22 May 2018).

24. Chung, K.M.; Chou, C.C.; Chang, K.C.; Chen, Y.J. Wind loads on a residential solar water heater. J. Chin. Inst. Eng. 2013, 36, 870-877. [CrossRef]

25. Chung, K.; Chang, K.-C.; Liu, Y. Reduction of wind uplift of a solar collector model. J. Wind Eng. Ind. Aerodyn. 2008, 96, 1294-1306. [CrossRef]

26. Irwin, H.; Cooper, K.; Girard, R. Correction of distortion effects caused by tubing systems in measurements of fluctuating pressures. J. Wind Eng. Ind. Aerodyn. 1979, 5, 93-107. [CrossRef]

27. Menter, F.R. Two-equation eddy-viscosity turbulence models for engineering applications. AIAA J. 1994, 32, 1598-1605. [CrossRef]

28. Shih, T.H.; Liou, W.W.; Shabbir, A.; Yang, Z.; Zhu, J. A new k- $\varepsilon$ eddy-viscosity model for high Reynolds number turbulent flows-Model development and validation. Comput. Fluids 1995, 24, 227-238. [CrossRef]

(C) 2019 by the authors. Licensee MDPI, Basel, Switzerland. This article is an open access article distributed under the terms and conditions of the Creative Commons Attribution (CC BY) license (http://creativecommons.org/licenses/by/4.0/). 